\title{
Phenolic Content and Antioxidant Capacity of Selected Underutilized Fruits Grown In Sri Lanka
}

\author{
A.L.I. Piyathunga, M.A.L.N. Mallawaarachchi ${ }^{1}$ and W.M.T. Madhujith ${ }^{2 *}$ \\ Postgraduate Institute of Agriculture \\ University of Peradeniya \\ Sri Lanka
}

\begin{abstract}
The present study was carried out to evaluate the total phenolic content and antioxidant properties of four selected underutilized fruits species: Manilkara hexandra (Roxb.) Dubard (Palu), Salacia chinensis L. (Himbutu), Schleichera oleosa (Lour.) Oken (Koan) and Eugenia uniflora (Cherry) grown in Sri Lanka. Antioxidative constituents were extracted into water and the antioxidant activity of fruit extracts was assessed using biochemical assays: 1,1-diphenyl-2(2,4,6-trinitrophenyl) hydrazine (DPPH) radical scavenging assay $(n=3)$ and ferric reducing power assay $(F R A P)(n=3)$. The total phenolic content was estimated using Folin-Ciocalteu's colorimetric assay and expressed as milligrams of gallic acid equivalents per $100 \mathrm{~g}$ of both fresh and dry weight of fruit. The fruit extracts tested exhibited a broad range of antioxidant activity as measured by DPPH radical scavenging and FRAP assays. The highest antioxidant activity was exhibited by Manilkara hexandra (Palu) in both assays performed. Furthermore, it was observed that the antioxidant activity as measured by the DPPH radical scavenging activity and FRAP assay strongly correlated $\left(R^{2}=0.997\right)$ with total phenol content for extracts of all four underutilized fruit species tested. Therefore, the antioxidant activity of the fruits could be attributed to phenolic compounds present in the samples. This is the first time that antioxidant potential of some of the above fruits is reported.
\end{abstract}

Keywords: Antioxidant activity, DPPH, FRAP, Total phenolic content, Underutilized fruits of Sri Lanka

\section{INTRODUCTION}

Fruits are rich sources of phytochemicals especially phenolic antioxidants. Antioxidants from plant materials terminate the action of free radicals which are spontaneously generated in the body thereby protecting the body from a myriad of diseases (Lai et al., 2001). Increased intake of fruits and vegetables can be considered an important means of increasing the concentration of antioxidants in plasma (Maurizio and Bruno, 2006). Fruit and vegetable consumption has been linked to reduced cardiovascular diseases and stroke. Furthermore, a new scientific base is emerging to support the protective role of fruits and vegetables in prevention of cataract formation, age related macular degeneration, chronic obstructive pulmonary disease, diverticulosis and other digestive disorders and hypertension. Phenolic compounds from plants possess strong antioxidant activity thus help protect the body cells against oxidative damage caused by free-radicals (Kahkonen et al., 1999). Beneficial effects

Regional Agriculture Research and development Centre, Diyathalawa Road, Bandarawela, Sri Lanka.

2 Department of Food Science and Technology, University of Peradeniya, Peradeniya, Sri Lanka

Corresponding author: madujith@yahoo.com 
of phytochemicals are mainly attributed to their antioxidant potential thus it is of paramount importance to assess the antioxidant efficacy of fruit extracts. The total antioxidant potential (TAP) is a relevant tool for investigating the relationship between dietary antioxidants and pathologies induced by the oxidative stress (Pisoschi and Negulescu, 2011). This was confirmed by the data obtained from a population-based control study, proving that dietary TAP resulted in reduced risk of both cardiac and distal gastric cancer (Serafini et al., 2002). The evaluation of the total antioxidant capacity (TAC) may be an appropriate tool to determine the additive antioxidant properties of plant foods (Pellegrini et al., 2003).

It is estimated that there are more than 230 fruit species belonging to 57 plant families grown in Sri Lanka, most of which remain underutilized. Many of the underutilized species such as, Nelli, Beli, wood apple and Annona have long been used for their medicinal properties (Pusupakumara et al., 2007). These fruit species are rich in phytochemicals such as carotenoids, sterols, saponins, terpenes, anthocyanins, phenolic acids, catechins and other polyphenolics. Phytochemical components such as phenolics, ascorbic acid and carotenoids may have direct influence over the radical-scavenging potential (Diplock et al., 1998).

Manilkara hexandra (Roxb.) Dubard, Palu belongs to family Sapotacea, dominated in tropical dry mixed evergreen forests (Wadugodapitiya et.al, 2013), especially in Wanni district and southeastern part of the country. M. hexandra is considered as one of the most valuable timber species in the forest. The fruits are useful for treating bronchitis, urethrorrhea and leprosy (Longman, 2004). The bark is also recommended for fever, jaundice, helminthiasis and flatulence (Gopalkrishnan et al., 2014). The roots are used to treat headache (Rao et al., 2010) while seeds are used in pharmacology. However, there are no reports on antioxidant efficacy of fruit pulp of $M$. hexandra. The present study was carried out to evaluate the antioxidant properties of M. hexandra Salacia chinensis L. (Himbutu), Schleichera oleosa (Lour.) Oken (Koan) and Eugenia uniflora (Cherry). Salacia chinensis L. (Himbutu) belonging to the family Hippocrateaceae is a woody climbing shrub that thrives well in wetlands of Sri Lanka. All parts of the plant are traditionally used in Ayurveda: ripe fruits and roots are used in indigenous medicine to treat diabetes mellitus, amenorrhoea, dysmenorrhoea and sexually transmitted diseases. Stems of $S$. chinensis have been extensively used for carminative, emmenagogue, blood tonic, cardio tonic, antiinflammatory, antidiabetic purposes and the treatment of rheumatism, leucorrhea and stimulated lochial excretion (Govindaraj et al., 2009). Schleichera oleosa (Lour.) Oken a member of family Sapindaceae is commonly known as Koan in Sri Lanka. It has potential of anticancer, antioxidant and antimicrobial activities and contains various polyphenolic compounds (Bhatiya et al., 2013). The stem bark of $S$. oleosa is used as astringent and antipyretic, also useful in pruritus, adenitis, ripening boils, nostalgia, arthalgia, malaria, inflammations and ulcers (Shrinivas and Baboo, 2013). In 2015, Thatavong and Athipornchai concluded that presence of terpinoids, flavonoids, tannins and steroids in methanolic extracts of fruits of $S$. oleosa is evident for the antioxidant action of fruit. Eugenia uniflora L. family Myrtaceae commonly known as Brazilian cherry or Cherry, cultivated mostly in home gardens and small-scale agriculture farms in Sri Lanka. Besides being highly desirable for fresh consumption, the E. uniflora fruits are also used for juice and ice cream production (Celli et al., 2011). Its leaves are used in popular medicine as infusion in the treatment of fever, rheumatism, stomach diseases and disorders of the digestive tract, hypertension, yellow fever, and gout. It may also reduce weight, blood pressure, and serve as a diuretic (Adebajo et al., 1989).

The most commonly used methods for measuring antioxidant activity are those that involve the generation of free radical species which are then neutralized by antioxidant compounds 
(Arno et al. 2001). The objective of the present study was to evaluate four selected underutilized fruit species grown in Sri Lanka as a source of natural antioxidants using in vitro biochemical assays.

\section{MATERIALS AND METHODS}

\section{Samples}

Manilkara hexandra (Roxb.), Salacia chinensis (Himbutu), Schleichera oleosa (Lour.) Oken (Koan), Eugenia uniflora (Cherry) fruits were collected from their natural habitats in Badulla and Kilinochchi districts. Fig. 1 illustrates the fruit species selected for the study.

\section{Chemicals and reagents}

Folin Ciocalteau's reagent, gallic acid, 2,2-diphenyl-1-picrylhydrazyl hydrate (DPPH), 2, 2azobis (2-ethylbenzothiazoline-6-sulfonic acid), 2, 4, 6-tris (2-pyridyl)-1, 3, 5-triazine (TPTZ), ethyl acetate, methanol and concentrated sulfuric acid were purchased from Sigma Aldrich, USA. All chemicals were of analytical or higher grades.

\section{Preparation of fruit extracts}

The edible portion of the fruits $(10 \mathrm{~g})$ was homogenized with accurately measured distilled water $(30 \mathrm{ml})$. The homogenate was placed on a reciprocating shaker at $150 \mathrm{rpm}$ for $90 \mathrm{~min}$ at ambient temperature. The mixture was centrifuged at $4,500 \mathrm{~g}$ for $10 \mathrm{~min}$ and the supernatant was filtered through Whatman number 1 filter paper. The extraction was repeated twice with the residue and the supernatants were combined, lyophilized and stored at $-20{ }^{\circ} \mathrm{C}$ until analysis.
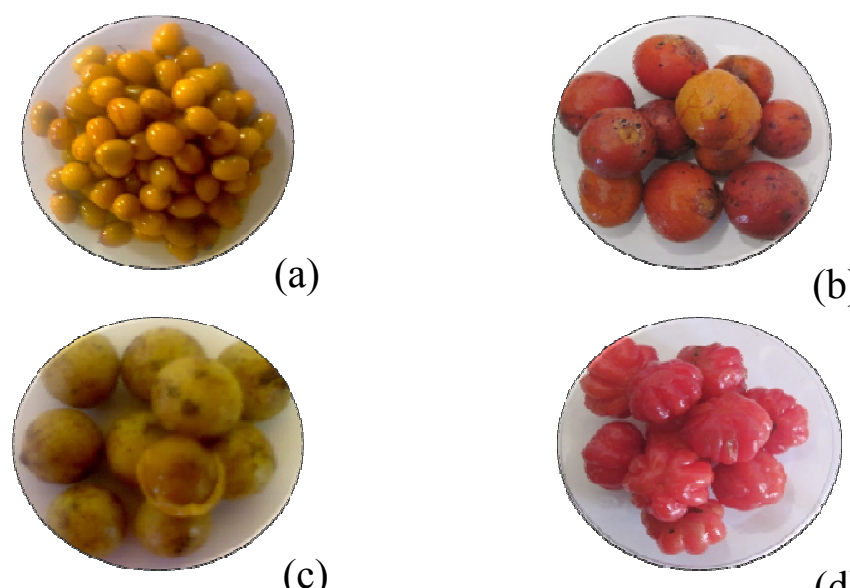

(b)

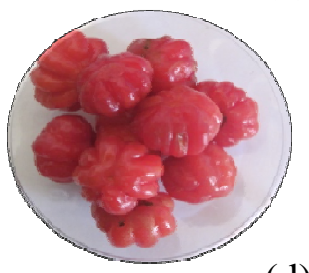

(d)

Fig. 1. Fresh fruits of Manilkara hexandra (a), Salacia chinensis (b), Schleichera oleosa (c) and Eugenia uniflora (d). 


\section{Total Phenolic Content of Fruit extracts}

Total phenolic content of aqueous extracts was determined using Folin-Ciocalteu's colorimetric method explained by (Hassimotto et al., 2009) using gallic acid as the standard. The absorbance was measured using spectrophotometer (mrc, UV-18, UK) at $765 \mathrm{~nm}$ and expressed as milligrams of gallic acid equivalents (mg GAE) per $100 \mathrm{~g}$ of fresh weight (FW) and dry weight (DW).

\section{DPPH Radical Scavenging Activity of Fruit extracts}

The radical scavenging activity of the aqueous extracts was assessed using modified 1, 1diphenyl-2-picrylhydrazyl (DPPH) assay (Jagtap et al., 2010). The stock solution was prepared by dissolving $10 \mathrm{mg}$ of DPPH in $25 \mathrm{ml}$ of methanol. The working solution was prepared by mixing $5 \mathrm{ml}$ of stock solution with $60 \mathrm{ml}$ methanol to obtain an absorbance of $0.348 \pm 0.02$ at $517 \mathrm{~nm}$. Different dilutions of the extracts were prepared in triplicate. An aliquot of $800 \mu \mathrm{L}$ of $0.093 \mathrm{mM} \mathrm{DPPH}$ radical in methanol was added to a test tube containing $400 \mu \mathrm{L}, 200 \mu \mathrm{L}$ and $100 \mu \mathrm{L}$ of the sample separately. The reaction mixture was vortexed for $30 \mathrm{~s}$ and left to stand at room temperature $\left(25^{\circ} \mathrm{C}\right)$ in dark for $30 \mathrm{~min}$. The percentage of remaining radical in medium is calculated as the absorbance of the sample divided by that of DPPH control at the same time multiplied by 100. The amount of sample needed to decrease the initial DPPH concentration by $50 \%, \mathrm{EC}_{50}$, was calculated.

$$
\mathrm{EC}_{50}=\left\{1-\left(\mathrm{A}_{\text {sample }} / \mathrm{A}_{\text {control }}\right)\right\} * 100
$$

Where $\quad \mathrm{A}_{\text {sample }}=$ Absorbance of sample at $517 \mathrm{~nm}$

$\mathrm{A}_{\text {control }}=$ Absorbance of Control at $517 \mathrm{~nm}$

\section{Ferric reducing antioxidant power of Fruit extracts}

Ferric reducing antioxidant power (FRAP) assay was performed according to Benzie and Strain (1996) and Faria et al. (2005) with some modifications. Briefly, the working FRAP reagent produced by combination of $150 \mathrm{mM}$ acetate buffer ( $\mathrm{pH} \mathrm{3.6),} 5 \mathrm{mM} \mathrm{2,4,6-}$ tripyridyl-s-triazine (TPTZ) and $10 \mathrm{mM} \mathrm{FeCl}_{3} \cdot 6 \mathrm{H}_{2} \mathrm{O}$ at $10: 1: 1$ ratio prior to use and heated to $37^{\circ} \mathrm{C}$ in a water bath for $10 \mathrm{~min}$. One milliliter of FRAP reagent at $37^{\circ} \mathrm{C}$ was mixed with 50 $\mu 1$ of sample and the solution was vortexed for 30s. After 4 min absorbance was read at absorbance $593 \mathrm{~nm}$ using UV-Visible spectrophotometer (Shimadzu, UV, Japan). The results were expressed as $\mathrm{mM}$ of $\mathrm{Fe}^{2+} / \mathrm{g}$ dry weight using a $\mathrm{Fe}^{2+}(1.25-20 \mathrm{mM})$ standard curve.

\section{Statistical analysis}

Data are represented as mean $\pm \mathrm{SD}(\mathrm{n}=3)$. The results were analyzed using Minitab 15 software at significant level of $\mathrm{P}<0.05$. 


\section{RESULTS AND DISCUSSION}

\section{Total Phenolic Content of Fruit extracts}

The TPC of fruits ranged from $136.4 \pm 0.007$ to $316.54 \pm 0.042 \mathrm{mg}$ gallic acid equivalents per $100 \mathrm{~g}$ fresh fruit with Manilkara hexandra showing the highest TPC (Table 1).

Table 1. Total phenolic content of fruits expressed on fresh and dry weight basis

\begin{tabular}{lll}
\hline Fruit species & $\begin{array}{l}\text { mg of GAE/100g Fresh } \\
\text { weight basis }\end{array}$ & $\begin{array}{l}\text { mg of GAE/100g Dry } \\
\text { Weight basis }\end{array}$ \\
\hline Palu (Manilkara hexandra) & $316.54 \pm 0.04^{\mathrm{d}}$ & $1430.67 \pm 0.03^{\mathrm{d}}$ \\
Himbutu (Salacia chinensis) & $291.73 \pm 0.01^{\mathrm{c}}$ & $1376.09 \pm 0.13^{\mathrm{c}}$ \\
Koan (Schleichera oleosa) & $223.67 \pm 0.05^{\mathrm{b}}$ & $989.69 \pm 0.04^{\mathrm{b}}$ \\
Cherry (Eugenia uniflora) & $136.4 \pm 0.01^{\mathrm{a}}$ & $847.21 \pm 0.08^{\mathrm{a}}$ \\
\hline
\end{tabular}

Data are presented as Mean \pm SD $(n=3)$

Mean values in a column superscripted by different letters are significant at $\mathrm{p}<0.05$

The aqueous extracts of Palu (Manilkara hexandra) and Himbutu (Salacia chinensis) showed the highest total phenolic content while the lowest was observed in cherry (Eugenia uniflora). This implies that there is good antioxidative property in palu (Manilkara hexandra) and Himbutu (Salacia chinensis). The phenolic content of Palu fruit has not been reported in literature, however, the TPC of stem bark, leaves and root extracts has been reported.

Chavan et al. (2013) reported that the TPC of aqueous extract of Himbutu (S. chinensis) was $122 \pm 0.44 \mathrm{mg} \mathrm{GAE} / 100 \mathrm{~g}$ FW. According to Kubola et al. (2011), the TPC of methanolic extracts of freeze dried Koan (S. oleosa) was reported to be $739 \mathrm{mg}$ GAE g/100g DW of fruit. Bagetti et al. (2011) reported that TPC of Brazillian cherry (E. uniflora) to be $210 \pm 3$ $\mathrm{mg} \mathrm{GAE} / 100 \mathrm{~g} \mathrm{FW}$. The TPC of four fruit species studied, are higher than that of recorded in literature. These variations might be attributed to differences in growing environment, season, cultivar, soil and rainfall (Manach et al., 2004). When compared with other major fruit crops, these underutilized fruits recorded high TPC. The TPC in mango ranged from 32.06 to $139.71 \mathrm{mg} \mathrm{GAE} / 100 \mathrm{~g} \mathrm{FW}$ (Liu et al., 2013), $47.9 \mathrm{mg} \mathrm{GAE} / 100 \mathrm{~g}$ FW in pineapple, $57.6 \mathrm{mg}$ GAE/100g FW in papaya (Luximon-Ramma et al., 2003). As Folin-Ciocauteu reagent method was employed for TPC measurement, other reducing agents such as ascorbic acid, sugars and aromatic amines may also affect the results (Magalhães et al., 2008).

\section{DPPH Radical Scavenging activity of Fruit extracts}

DPPH radical scavenging activity was expressed as percent inhibition at different concentration $(750 \mathrm{ppm}, 1500 \mathrm{ppm}, 3000 \mathrm{ppm})$ of each extract. The DPPH radical scavenging capacity was expressed as $\mathrm{IC}_{50}$ (Table 2 ). 
Table 2. DPPH radical scavenging ability expressed as $\mathrm{IC}_{50}$ value

\begin{tabular}{lllll}
\hline Plant extract & \multicolumn{4}{l}{ DPPH Radical Scavenging Activity (\% inhibition) } \\
\hline & $750 \mathrm{ppm}$ & $1500 \mathrm{ppm}$ & $3000 \mathrm{ppm}$ & $\mathrm{IC}_{50}$ value \\
Palu (M. hexandra) & $54.94 \pm 1.82$ & $64.22 \pm 0.40$ & $68.93 \pm 1.82$ & $274 \pm 1.34^{\mathrm{d}}$ \\
Himbutu (S. chinensis) & $48.41 \pm 5.68$ & $54.59 \pm 2.43$ & $62.93 \pm 5.68$ & $1260 \pm 4.5^{\mathrm{c}}$ \\
Koan (S. oleosa) & $46.55 \pm 2.23$ & $51.53 \pm 1.42$ & $61.06 \pm 2.23$ & $1580 \pm 1.96^{\mathrm{b}}$ \\
Cherry (E. uniflora) & $12.35 \pm 2.64$ & $34.77 \pm 0.60$ & $53.59 \pm 2.64$ & $2797 \pm 1.96^{\mathrm{a}}$ \\
\hline
\end{tabular}

Data are presented as Mean \pm SD $(n=3)$

Aqueous extract of cherry (E. uniflora) showed the highest $\mathrm{IC}_{50}$ value indicating the lowest antioxidant capacity while Palu ( $M$. hexandra) showed the highest antioxidant capacity. There are no literature data available on the antioxidant capacity of fruit pulp of Palu.

\section{Ferric Reducing Antioxidant Power of Fruit extracts}

Standardization of FRAP assay was carried out by reacting TPTZ with $\mathrm{FeSO}_{4}$. The ferric reducing antioxidant potential of the samples was calculated using $\mathrm{Fe}^{2+}$ standard curve and expressed as equivalent to that $\mathrm{Fe}^{2+} \mathrm{mM} / \mathrm{g}$ of fresh extract. FRAP values of the samples tested ranged from $0.50 \pm 0.00$ to $4.23 \pm 0.01 \mathrm{Fe}^{2+} \mathrm{mM} / \mathrm{g}$ of extract. Aqueous extract of Palu $(M$. hexandra) displayed significantly $(\mathrm{p}<0.05)$ higher ferric reducing antioxidant potential than the other fruit extracts as shown in Table 3.

Table 3. - FRAP value of aqueous fruit extracts

\begin{tabular}{ll}
\hline Fruit & $\begin{array}{l}\text { FRAP assay equivalent to } \mathbf{F e}^{2+} \mathbf{~ m M} / \\
\text { g Fresh Weight basis }\end{array}$ \\
\hline Palu (M. hexandra) & $4.23 \pm 0.00^{\mathrm{a}}$ \\
Himbutu (S. chinensis) & $3.13 \pm 0.02^{\mathrm{b}}$ \\
Koan (S. oleosa) & $1.12 \pm 0.01^{\mathrm{c}}$ \\
Cherry (E. uniflora) & $0.50 \pm 0.00^{\mathrm{d}}$ \\
\hline
\end{tabular}

Data are presented as Mean $\pm \mathrm{SD}(\mathrm{n}=3)$

\section{Correlation between Antioxidant activity and Total Phenol Content}

Many studies have demonstrated a strong relationship between total phenolic content and antioxidant activities in different foods (Yang et al., 2004; Kriengsak et al., 2006). In the present study, a fairly strong correlation was observed between total phenolic content of Palu (Manilkara hexandra) and DPPH and FRAP of Palu extracts (Figures 2 and 3). 


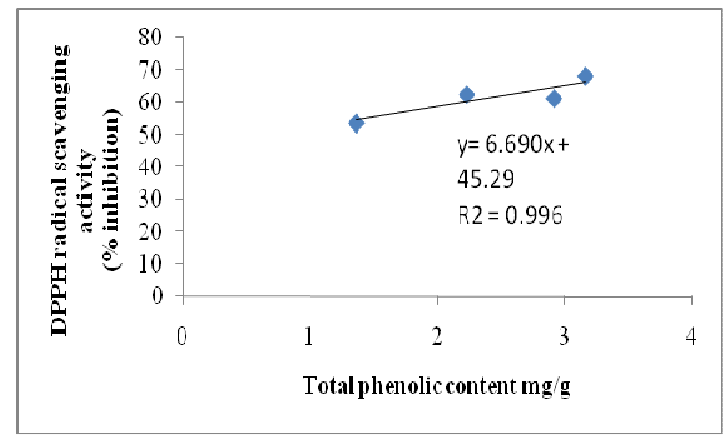

Fig.2. Correlation between DPPH radical scavenging activity and Total Phenol Content of each fruit extract in different concentration

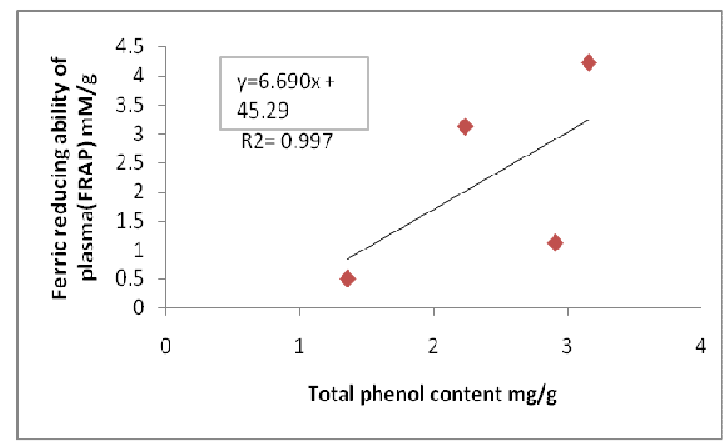

Fig. 3. Correlation between FRAP essay and Total Phenol Content of each fruit extract in different concentration

A fairly strong positive correlation is observed between TPC with DPPH radical scavenging activity $\left(\mathrm{R}^{2}=0.996\right)$ as well as a strong correlation $\left(\mathrm{R}^{2}=0.997\right)$ was observed for TPC and FRAP values obtained for fruit extracts. The strong correlation between TPC and antioxidant capacity as measured by DPPH radical scavenging capacity and FRAP indicate that the phenolic compounds present in the fruits are mainly attributed for the observed antioxidant properties.

\section{CONCLUSIONS}

Out of the four selected underutilized fruit species for the evaluation of antioxidant activities, Manilkara hexandra exhibited the highest antioxidant capacity. The phenolic content displayed strong positive correlation with antioxidant activity of the species namely, Manilkara hexandra followed by the Salacia chinensis. The differences in the antioxidant activities among the fruits could be attributed to their differences in phenolic contents and compositions present in the samples. 


\section{REFERENCES}

Adebajo, A.C., Oloki, K.J. and Aladesanmi, A. (1989). Antimicrobial activity of the leaf extract of Eugenia uniflora. Journal of Phytotherapy Resource. 3(6), 258 - 259.

Arno, M.B., Canao, A. and Acosta, M. (2001). The hydrophilic and lipophilic contribution to total antioxidant activity. Food Chem. 73, 239-244.

Benzie, I.F. and Strain, J.J. (1996). Ferric reducing ability of plasma (FRAP) as a measure of antioxidant power: the FRAP assay. Anal Bio-chem. 239, $70-76$.

Bagetti, M. (2011). Physicochemical characterization and antioxidant capacity of pitanga fruits (Eugenia uniflora L.). Ciência e Tecnologia de Alimentos. 31(1), 147-154.

Benzie, I.F.F. and Strain, J.J. (1996). Ferric reducing ability of plasma (FRAP) as a measure of antioxidant power: The FRAP assay. Anal Biochem. 239, 70 - 76.

Bhatiya H., Kaur, J., Nandi, S., Gurnani, V., Chowdhury, A., Reddy, P.H., Vashishtha, A. and Rathi, B. (2013). A revieve on Schleichera oleosa: Pharmacological and environmental aspects. J. of Phar. Res. 6, 224 - 229.

Celli, G.B., Pereira-Netto, A.B. and Beta, T. (2011). Comparative analysis of total phenolic content, antioxidant activity and flavonoids profile of fruits from two varieties of Brazilian cherry (Eugenia uniflora L.) throughout the fruit development stages. Food Res. Inter. 44, $2442-2451$.

Chavan, J.J., Jagtap, U.B., Gaikwad N.B., Dixith G.B. and Bapat V.A. (2013). Total phenolics, flavonoids and antioxidant activity of Saptarangi (Salacia chinensis L.) fruit pulp. J. Plant Biochem. Biotechnol. 22(4), 409 - 413.

Diplock, A. T. (1998). Functional food sciences and defense against reactive oxidative species. British Journal of Nutrition. 80(1), 77-112.

Faria, A., Oliveira, J., Neves, P., Gameiro, P., Santos-Buelga, C. and Freitas, V. (2005). Antioxidant properties of prepared blueberry (Vaccinium myrtillus) extracts. J. Agr. Food Chem. 53(17), 6896-6902.

Kriengsak, T., Unaroj, B., Kevin, C., Luis, C. and David, H.B. (2006). Comparison of ABTS, DPPH, FRAP, and ORAC assays for estimating antioxidant activity from guava fruit extracts. J. Food Comp. Anal. 19, 669 - 675.

Gopalkrishnan B., Shimpi, L.S.N. and Ringmichon, C.L. (2014). Stem bark of Manilkara hexandra (Roxb.) Dubard - Pharmacognosy. Wld J. Phar \& Pharmaceutical Sci. 3(2), 25032511.

Govindaraj Y., Melanphuru, V., Agrahari, V., Gupta, S. and Nema, R.K. (2009). Genotoxicity studies of Mangiferin isolated from Salacia chinensis Linn. Acad. J. Plant Sci. 2(3), 199 - 204 
Jagtap, S., Gore, S., Yavankar, S., Pardesi, K. and Chopade, B. (2010). Indian Journal of Experimental Biology. 48, 936.

Kahkonen, M.P., Hopia, A.I., Vuorela, H.J., Rauha, J.P., Pihlaja, K., Kujala, T.S. and Heinonen, M. (1999). Antioxidant activity of plant extracts containing phenolic compounds. J. Agric. Food Chem. 47, 3954 - 3962.

kubola J., Siriamornpun, S. and Meeso, N. (2011). Phytochemicals, vitamin C and sugar content of Thai wild fruits. Food Chem. 126, 972 - 981.

Lai, L.S. and Chou, S.T. (2001). Studies on the antioxidative activities of Hsiantsao (Mesona procumbens Hemsl.) leaf gum. J.Agric. Food Chem. 49, 963 - 968.

Lima, V. L. A. G., Melo, E. A. and Lima, D. E. S. (2002). Fenolicose carotenoids to taisempitanga. Scientia Agricola. 59(3), 447-450.

Liu, F., Fu, S. and Bi, X. (2013). Physico-chemical and antioxidant properties of four mango (Mangifera indica L.) cultivars in China. Food Chem. 138, 396 - 405.

Longman, O. (2004). Manilkara Hexandra (Roxb.) Dubard in Indian Medicinal Plants a compendium of 500 species. Dubard. 3, 393-394.

Luximon-Ramma, A., Bahorun, T. and Crozier, A. (2003). Antioxidant actions and phenolic and vitamin C contents of common Mauritian exotic fruits. J Sci Food and Agri. 83, $496-$ 502.

Magalhães, L.M., Segundo, M.A., Reis, S. and Lima, J.L.F.C. (2008). Methodological aspects about in vitro evaluation of antioxidant properties. Anal. Chim. Acta. 613, 1 - 19.

Manach, C., Scalbert, A., Morand, C., Rémésy, C. and Jiménez, L. (2004). Polyphenols: Food sources and bioavailability. Am. J. Clin. Nutr. 79, 727 - 747.

Maurizio, B. and Bruno, M. (2006). Update on fruit antioxidant capacity: a key tool for Medirerranean diet. Public Health Nutrition. 9, 84.

Pellegrini, N., Serafini, M., Colombi, B., Del Rio, D. and Salvatore, S. (2003). Total antioxidant capacity of plant foods, beverages and oils consumed in Italy assessed by three different in vitro assays. J Nutr. 133, $2812-2819$.

Pisoschi, A.M. and Negulescu, G.P. (2011). Methods for Total Antioxidant Activity Determination: A Review. Biochem \& Anal Biochem. 1, 106.

Pushpakumara, D.K.N.G. and Heenkenda, H.M.S. (2007). Nelli (Amla) Phyllanthus emblica L. Chapter 6, pp. 180 - 221. In: Pushpakumara, D.K.N.G., Gunasena, H.P.M. and Singh, V.P. (eds) Underutilized fruit trees in Sri Lanka. Volume 1. World Agroforestry Centre, South Asia Office, New Delhi, India.

Rao, D.S., Venkaiah, M., Padal, S.B. and Murty, P.P. (2010). Ethnomedicinal plants from Paderu division of Visakhapatnam district, A.P., India. J. Phytol. 2(8), 70 - 91. 
Serafini, M., Bellocco, R., Wolk, A. and Ekstrom, A.M. (2002) Total antioxidant potential of fruit and vegetables and risk of gastric cancer. Gastroenterology. 123, 985 - 999.

Southon, S. and Faulks, R. (2002). Health benefits of increased fruit and vegetable consumption in Fruit and Vegetable Processing improving Quality. Ed. Wim Jongen. Woodhead Publishing Limited, Abington Hall, Abington Cambridge CB1 6AH, England. pp. $5-22$.

Srinivas, K. and Baboo R.V.C. (2013). Antioxidant activity of ethonolic extracts of stem bark of Schleichera oleosa (Lour.) Oken. Inter. J. of Pharmacotherapy. 3(1), 12 - 14.

Thatavong, X. and Athipornchai, A. (2015). Phytochemical analysis and antioxidant evaluation from Ceylon Oak (Schleichera oleosa) fruits. Proceeding of Pure and applied Chemistry Conference. pp. 497-500.

Wadugodapitiya, A., Weeratunga, V., Goonatilake, S. de A., Chandranimal, D., Perera, N., and Asela, C. (2013). Insights into the biodiversity of the Sampur area in Trincomalee. Occ. pap. IUCN, Sri Lanka. International Union for Conservation of Nature, Sri Lanka. pp. 54.

Yang, J., Meyers, K.J., van der Heide, J. and Liu, R.H. (2004). Varietal differences in phenolic content and antioxidant and anti-proliferative activities of onions. J. Agric. Food Chem. 52, 6787 - 6793. 